\section{A EDUCAÇÃO VOLTADA PARA OS DESAFIOS DO SÉCULO XXI: PROTAGONISMO, TECNOLOGIAS E SUSTENTABILIDADE}

\author{
EDUCATION AIMED FOR THE CHALLENGES OF TEH XXI \\ CENTURY: PROTAGONISM, TECHNOLOGIES AND \\ SUSTAINABILITY
}

Ana Paula Waltrick ${ }^{1}$

Mestranda na Universidade do

Planalto Catarinense (UNIPLAC),

Educação (PPGE), Mestrado

Acadêmico. E-mail:

aninha@uniplaclages.edu.br.

\section{Cristina Buogo 2}

Mestranda na Universidade do Planalto Catarinense (UNIPLAC), Programa de Pós-Graduação em Educação (PPGE), Mestrado Acadêmico. E-mail:

cristinabuogo@uniplaclages.edu.br

Marieli Paim de Lima ${ }^{3}$ Mestranda na Universidade do Planalto Catarinense (UNIPLAC), Programa de Pós-Graduação em Educação (PPGE), Mestrado Acadêmico. E-mail:

marielilimap@uniplaclages.edu.br.

Raquel Maciel Lopes ${ }^{4}$ Mestranda na Universidade do Planalto Catarinense (UNIPLAC), Programa de Pós-Graduação em Educação (PPGE), Mestrado

Acadêmico. E-mail:

raquelmlopes@uniplaclages.edu.br.

\section{Vanice dos Santos 5}

Doutora em Educação (UFRGS). Docente pesquisadora no Programa de Pós-Graduação em Educação da Universidade do Planalto Catarinense (PPGE/UNIPLAC). E-mail: profa.vanice@uniplaclages.edu.br

\section{RESUMO}

O presente trabalho tem como objetivo refletir acerca dos desafios do século XXI estruturados pela sustentabilidade, pelas tecnologias e pelo protagonismo. A fim de conduzir essa reflexão, buscou-se compreender as contribuições das tecnologias para o desenvolvimento sustentável, bem como para a construção de cidades humanizadas. Na segunda seção, reflete-se sobre o protagonismo como formação de uma consciência crítica para o potencial transformador. Para tanto, a pesquisa foi desenvolvida na modalidade Revisão de Literatura, mediante análise de textos com autores vinculados às temáticas educacionais, sociais e filosóficas. Dessa forma, conclui-se que para edificação de uma Cidade Humanizada é preciso ressignificar as relações entre os sujeitos e destes com o Estado. As tecnologias são importantes para os avanços e inovações em diversos campos, porém é preciso pensar em alternativas para que estas sejam potencializadoras das mudanças sociais, rompendo com as amarras do capitalismo cruel, excludente, e eficaz na degradação do ser humano. Então, a tecnologia não pode ser pensada apenas pelo objeto em si, mas também pela sua funcionalidade a serviço das mais variadas possibilidades humanas, tais como saúde, bem-estar, sustentabilidade e solidariedade. Sendo assim, a partir da problematização do conceito de ética, compreende-se que embora a globalização enfatize este conceito relacionado à lógica de mercado, na perspectiva humana ele tem outro significado, muito mais comprometido com ideias relacionadas à emancipação dos sujeitos.

PALAVRAS-CHAVE: Autonomia, Cidades Humanizadas, Desenvolvimento Sustentável. 


\section{ABSTRACT}

This research aims to reflect upon the challenges of the XXI Century structured by sustainability, technologies and protagonism. As to have such reflection in place, we aimed to understand the contribution of technologies towards sustainable development, and the building of humanized cities. In the second section, we shall reflect upon Protagonism as the formation of critical thinking for the transforming potential. In order to achieve so, the research herein was developed in the modality Literary Review through text analysis; authors are connected to themes such as education, sociology and philosophy. Thus we have concluded that for the purpose of the construction of a humanized city it is necessary to reconceptualize the relationship among subjects and their relationship with the State. Technologies are important for the advancement and innovation in many a field, therefore, it is pivotal to think of potentializing alternatives for social changes. Therefore, technology cannot be perceived as a subject per se, but also as functionality serving the most diverse human possibilities such as health, well-being, sustainability and solidarity. All in all, as of the problematization of the concept of ethics, we understand that despite the fact that globalization emphasizes that concept based upon the logics of the market; in the human perspective it has other meaning, much more committed to the ideas related to the emancipation of the subjects.

KEYWORDS: Autonomy, Humanized Cities, Sutainable development.

\section{INTRODUÇÃO}

Este artigo objetiva refletir acerca dos desafios do século XXI estruturados pela sustentabilidade, pelas tecnologias e pelo protagonismo. Provocando um olhar a respeito das reais necessidades enquanto cidadãos, abandonando a perspectiva capitalista e direcionando às questões que favorecem a concepção de sujeitos humanizados. A fim de conduzir essa reflexão, buscou-se compreender as contribuições das tecnologias para o desenvolvimento sustentável, bem como para a construção de cidades humanizadas. Na segunda seção, reflete-se sobre o protagonismo enquanto formação de uma consciência crítica para o potencial transformador.

Desde a Conferência de Estocolmo, na década de 70, as discussões acerca da demanda pelo Desenvolvimento Sustentável têm sido fomentadas por organizações, pesquisadores e chefes de estado. A atual situação planetária demonstra a relevância da articulação equitativa entre as dimensões sociais, ambientais atreladas ao viés econômico para a promoção dos Direitos Humanos.

Neste sentido, durante o ano de 2015, a Organização das Nações Unidas (ONU) promoveu um encontro entre os líderes e representantes mundiais dos 193 países que integram esta Organização, na cidade de Nova York para discutir 0 desenvolvimento sustentável objetivando diminuir as mazelas humanas. Durante este encontro foi elaborado um plano de ação visando o fortalecimento da paz mundial, sendo que todos os países participantes foram signatários, inclusive o Brasil. Salienta-se que este plano de ação expressa os desafios para o presente século, o qual implica na viabilização de políticas públicas visando a sustentabilidade, a utilização das tecnologias para a construção de cidades 
humanizadas, bem como da justiça social voltada para a autonomia potencializando as mudanças sociais e a promoção dos direitos humanos.

\section{METODOLOGIA}

Este artigo foi elaborado através da metodologia qualitativa baseada em levantamentos de pesquisa bibliográfica com autores da área filosófica, social e educacional: Aieta (2016), Dagnino (2014), Freire (1996), Jaeger (2001), Lévy (1996), Neto e Carvalho (2002), ONU (2015), Rohden (2009) e Santos (2013). A partir da escolha metodológica, buscou-se a consulta de referenciais teóricos pertinentes que subsidiam a compreensão e a argumentação de ideias no que se refere ao tema abordado.

A partir da temática do evento buscou-se obras de autores que embasam reflexões acerca dos conceitos abordados no presente artigo. A aproximação com estes autores ocorreu durante o percurso formativo no Mestrado Acadêmico em Educação da Universidade do Planalto Catarinense (UNIPLAC). Ainda, a fim de qualificar as discussões deste artigo, foram realizadas estratégias de pesquisas em Documentos oficiais disponibilizados pela Organização das Nações Unidas (ONU), bem como a busca de artigos sobre o tema, no banco de dados do Portal de Periódicos da CAPES, utilizando as categorias "tecnologia social" e "Desenvolvimento Sustentável", ambas com os filtros temporais entre os anos de 2015 a 2019, língua portuguesa e na área educacional. Deste modo os resultados obtidos foram 135 artigos para a primeira categoria e 2.283 para a segunda categoria. Então, a partir destes resultados foram selecionados aproximadamente 10 artigos, dentre estes utilizou-se apenas um que articula a tecnologia social ao desenvolvimento sustentável.

\section{DESENVOLVIMENTO}

A globalização impulsionou novas relações de negócios entre os países, e, também, um grande crescimento e progresso tecnológico, ocasionando grande impacto nas sociedades. Sabe-se, de acordo com Lévy (1996) que a tecnologia ao longo dos anos tem transformado a maneira como a sociedade estrutura-se. Para Dagnino (2014) é preciso considerar a pluralidade das tecnologias, não somente a tecnologia convencional, com vistas ao mercado capitalista. O autor explana acerca da tecnologia social vindo a propor uma mudança do paradigma capitalista para um paradigma social de inclusão e sustentabilidade. É possível perceber que desde muito tempo as cidades tentam modernizar-se, onde cada uma apresentou características e qualidades, considerando as especificidades do local onde estavam inseridas. A pesquisadora Aieta (2016) utiliza o tema "Cidade Humana" para aquelas comunidades que estão relacionando-se de uma nova forma.

Desde a Grécia de Aristóteles, pensava-se em cidade como uma sociedade política voltada para a felicidade, para o bem de todos, pois o homem não pode viver de outra maneira, senão em sociedade. Então, a cidade nasce da aliança entre várias grupos, famílias, associação religiosa e política, formando uma aglomeração de pessoas, onde estabelece-se um local de reunião, o local de vida comum. Para Berman (2007, apud AIETA, 2016, p. 1626) a "cidade é o lugar para nós e para aqueles que virão depois de nós; o lugar para os que continuarão lutando para fazer com que nos sintamos em casa neste mundo". Nesta perspectiva, dentre os pressupostos da paideia grega estava 0 entendimento da formação do ser através dos valores éticos e políticos. Dessa 
maneira, estavam interligadas a filosofia e a pedagogia, compreendidas como um ideal intelectual, inter-relacionado. O conhecimento visava o bem da polis. A partir da construção da cidadania projetava-se a edificação do Estado ideal. Assim, de acordo com Rohden (2009), a paideia grega pautava-se sobretudo em uma filosofia de vida, cujos atos e intenções deveriam priorizar o bem, o belo, o justo e a verdade.

Neste sentido Santos (2013) realiza reflexões acerca das possibilidades que a mediação tecnológica pode proporcionar à formação do sujeito, como ferramenta para a propagação da criatividade humana, produção de cultura, das artes e ciências. A autora discorre sobre o Cuidado de Si socrático numa abordagem foulcaultiana, onde o princípio de toda e qualquer vida racional vinculada a paideia, precisa ser conduzido para a formação de um sujeito pleno para a polis, pois somente quem cuida de si é capaz de cuidar dos outros.

Contudo Aieta (2016) refere-se ao atual panorama social da vida na cidade como "Arquitetura do medo", em virtude das preocupações ocasionadas pelo sentimento de vulnerabilidade frente a violência. Em contrapartida a autora enfatiza que esse sinal de violência não pode distanciar o ideal de conquista de uma cidade sociológica, um espaço de vida comum com cidadania, que contempla o direito à habitação, garantia dos direitos sociais a fim de suprir as necessidades humanas não só de sobrevivência, mas de existência.

Quanto às prioridades da vida dos seres humanos, Aieta (2016) explana que deveria ser central a preocupação com o seu bem-estar e com a felicidade. Ressalta a importância de políticas públicas que favoreçam o planejamento de uma cidade humanizada. Enfatiza que as dualidades entre Estado e Sociedade foram construídas a partir do entendimento de que o governo representa o poder estatal, enquanto a sociedade é excluída do processo de decisão política. Segundo Aieta (2016), pensar em uma cidade inteligente significa considerar uma ressignificação das relações entre os indivíduos, destes com as instituições e com a economia. A partir desta relação, bem como da compreensão de seus direitos e deveres, os sujeitos poderão tornar-se protagonistas da sua própria história.

\section{O PROTAGONISMO ENQUANTO FORMACC̃O DE UMA CONSCIÊNCIA CRÍTICA PARA O POTENCIAL TRANSFORMADOR}

De acordo com Freire (1996), a educação deve ser um meio de intervenção no mundo. Explica que esta ação não está reduzida a aprendizagem dos conteúdos, mas principalmente a perceber a realidade cotidiana de forma ampliada. Afirma que é preciso estar atento a importância do que denomina de saber-fazer e o saber-ser da sabedoria. Que deve ser um exercício permanente, onde os homens e mulheres possam desenvolver através da ótica crítica, a percepção sobre as razões da degradação humana, bem como dos discursos relacionados à globalização, os quais aprisionam e retiram a essência do que nos torna humanos.

Neste sentido Netto e Carvalho (2012) atentam para o risco de nos tornarmos seres medíocres. Destacam que muitas vezes ao invés de assumir com protagonismo a nossa existência, repetimos comportamentos padronizados, reproduzindo o papel de opressores e oprimido, guiados pelos valores capitalistas tais como competitividade, individualidade e neutralidade. Ao falar em globalização, Freire (1996) adverte que a ética mercantil está distante da ética dos sujeitos. Nesta luta, entendemos que a educação representa um papel fundamental, onde poderá como ferramenta principal utilizar o conhecimento 
relacionado à experiência de vida. Sobre a relação entre a utilização de conhecimentos e a edificação da sociedade nos reportamos a paideia grega.

$\mathrm{Na}$ atual conjuntura da modernidade, presenciamos o que denominam de "revolução passiva operada pela burguesia capitalista" (NETTO; CARVALHO, 2012, p.38). Nesse contexto, dentre outras consequências, vivenciamos um enfraquecimento do exercício da cidadania, a substituição da solidariedade humana pela solidariedade mecânica proveniente do Estado, o enfraquecimento dos valores éticos os quais inviabilizam a percepção de referências necessárias às transformações sociais.

\section{CONSIDERAÇÕES FINAIS}

Por muito tempo a tecnologia convencional foi a base da estrutura econômica, um dos seus desafios atuais é auxiliar na sustentabilidade planetária. Para tanto, faz-se necessário pensar em um desenvolvimento que proporcione maior equidade e humanidade. Dessa forma, a tecnologia não pode ser pensada apenas pelo objeto em si, mas também pela sua funcionalidade a serviço das mais variadas possibilidades humanas, tais como saúde, bem-estar, sustentabilidade e solidariedade.

Entretanto, não é preciso condenar as tecnologias modernas, pois elas são importantes para os avanços e inovações em diversos campos, porém é preciso pensar em alternativas para que estas sejam potencializadoras das mudanças sociais, haja vista que as tecnologias são construídas, bem como servem ao humano de acordo com as suas intenções e prioridades.

Sendo assim, na perspectiva da edificação de uma cidade humanizada é preciso ressignificar a relações entre os sujeitos e destes com o Estado. Os conhecimentos adquiridos ao longo da vida devem possibilitar a percepção da realidade de uma forma crítica a fim de desenvolver a ação protagonista para a transformação da sua própria história. Esta postura poderá romper com as amarras do capitalismo cruel, excludente, e eficaz na degradação do ser humano. Sendo assim, de acordo com a problematização do conceito de ética compreende-se que embora a globalização enfatize este conceito relacionado à lógica de mercado, na perspectiva humana ele tem outro significado, muito mais comprometido com ideias relacionadas à emancipação dos sujeitos.

\section{AGRADECIMENTO}

Agradecemos à Fundação de Amparo à Pesquisa e Inovação de Santa Catarina - FAPESC (Termo de Outorga 2019TR70) pelo apoio.

\section{REFERÊNCIAS}

AIETA, Vania Siciliano. Cidades inteligentes: uma proposta de inclusão dos cidadãos rumo à ideia de cidade humana. Revista de Direito da Cidade. Rio de Janeiro, n.4, v. 08, 2016, p. 1622-164. Disponível em: https://www.epublicacoes.uerj.br/index.php/rdc/article/view/25427/19155. Acesso em: 05 maio 2019.

DAGNINO, Renato. A tecnologia social e seus desafios. In: Tecnologia Social: contribuições conceituais e metodológicas (online). Campina Grande: EDUEPB, 2014, p. 19-34. Disponível em: 
http://books.scielo.org/id/7hbdt/pdf/dagnino-9788578793272-04.pdf. Acesso em: 18 maio 2019.

FREIRE, Paulo. Pedagogia da autonomia: saberes necessários à prática educativa. 28 ed. Rio de Janeiro: Paz e Terra, 1996.

JAEGER, Werner Wilhelm. Paidéia: a formação do homem grego. Trad. Artur M. Parreira. 4. Ed. São Paulo: Martins Fontes, 2001.

LÉVY, Pierre. As tecnologias da inteligência. Trad. Carlos Irineu da Costa. São Paulo: Ed.34, 1996.

NETO, José Paulo; CARVALHO, Maria do Carmo B.. Cotidiano: conhecimento e crítica. São Paulo: Cortez, 2012.

ORGANIZAÇÃO DAS NAÇÕES UNIDAS, ONU. Transformando nosso mundo: a Agenda 2030 para o desenvolvimento sustentável, 2015.

ROHDEN, Luiz. Sobre a atualidade da paideia grega. In: CENCI, Angelo Vitório; DALBOSCO, Cláudia Almir; MÜHL, Eldon Henrique (Orgs). Sobre filosofia e educação: racionalidade, diversidade e formação pedagógica. Passo Fundo: Editora da UP, 2009, p. 103- 118.

SANTOS, Vanice dos. Ágora digital: o cuidado de si no caminho do diálogo entre tutor e aluno em ambiente virtual de aprendizagem. Jundiaí: Paco, 2013. 